\title{
A Case of Hodgkin Lymphoma Presenting as Nephrotic Syndrome
}

\author{
Dakhane $\mathrm{YR}^{1}$, Singh $\mathrm{RK}^{2}$, Thapar $\mathbf{R K}^{3}$
}

${ }^{1}$ Dr. Yogesh Rambhau Dakhane, MBBS, MD Resident, ${ }^{2}$ Dr. Rajesh Kumar Singh, MBBS, MD Pediatrics, Assistant Prof, ${ }^{3}$ Dr. Rajeev Kumar Thapar, MBBS, MD Paediatrics, Professor. All from the Department of Paediatrics, Command Hospital (CC) Lucknow, Uttar Pradesh, India.

Address for correspondence:

Dr. Rajesh Kumar Singh

Email: rrarri@yahoo.co.in

\section{How to cite}

Dakhane YR, Singh RK, Thapar RK. A Case of Hodgkin Lymphoma Presenting as Nephrotic Syndrome. J Nepal Paediatr Soc 2016;36(1):72-74.

doi: http://dx.doi.org/10.3126/jnps.v36i1.14623

This work is licensed under a Creative Commons Attribution 3.0 License.

\section{(c) (i)}

\begin{abstract}
Nephrotic changes as part of the paraneoplastic syndrome are rare in lymphoid malignancies. One percent of cases of Hodgkin's Lymphoma cases may present with nephritic syndrome. We are reporting a case which initially presented as nephritic syndrome and later was diagnosed to have of Hodgkin's Lymphoma and managed accordingly.
\end{abstract}

Key words: Nephrotic Syndrome, Hodgkin's Lymphoma, Retroperitonial lymphadenopathy

\section{Introduction}

araneoplastic glomerulopathy has been reported in patients with malignancy ${ }^{1}$. Nephrotic changes as part of the paraneoplastic syndrome are rare in lymphoid malignancies ${ }^{2}$. In particular, the association of nephrotic syndrome (NS) with Hodgkin's Lymphoma $(\mathrm{HL})$ is rare and there are few reports in the literature ${ }^{3,4,5}$. In the paediatric population an incidence of $1 \%$ has been described in France ( 5 patients out of 483 children with $\mathrm{HL}$ ) ${ }^{6}$. Minimal change nephropathy is the most frequently observed renal lesion whereas this association appears, either simultaneously or within several months of each other $r^{2,3,5,6,7}$.

\section{The Case}

A 12-year-old, boy was admitted with complaints of periorbital and lower-extremities oedema, weight gain. There was no history of fever or night sweats. There was no lymphadenopathy or hepatosplenomegaly. His serum albumin was $1.6 \mathrm{gm} / \mathrm{dl}$ and serum cholesterol was $268 \mathrm{mg} / \mathrm{dl}$. Urine protein was $3+$ and urine protein creatinine ratio was 2.2 .

With the diagnosis of NS, the initial treatment consisted of prednisolone. He achieved remission in 2 weeks. After 6 weeks of daily steriods he was put on alternate day prednisolone. Two months later while on alternate day prednisolone, in an ultrasound examinationon he was found to have had retroperitonial mesentric Lymphadenopathy (Fig 1). Lab parameters were $\mathrm{Hb}-8.5 \mathrm{gm} \%$, TLC11700 /cm, Urine: protein 4 + , A/G: 3.0/2.0, Serum cholesterol: 198, Blood urea/ S Cr: 35/0.7 mg/dl, Na/K: 141/3.8 mmol/l, HBV/HCV/HIV: 
Neg, LDH: 370U/L, CXR: NAD, CECT Chest+Abdomen was suggestive of Retroperitoneal Lymphadenopathy (Fig 2). Laproscopic Lymph Node biopsy done under GA which showed charactrestic of Hodgkin lymphoma of nodular sclerosis subtype (Fig 3). He was started on chemotherapy (ABVD). Presently he is in complete remission with no signs of NS found during the follow-up evaluations.

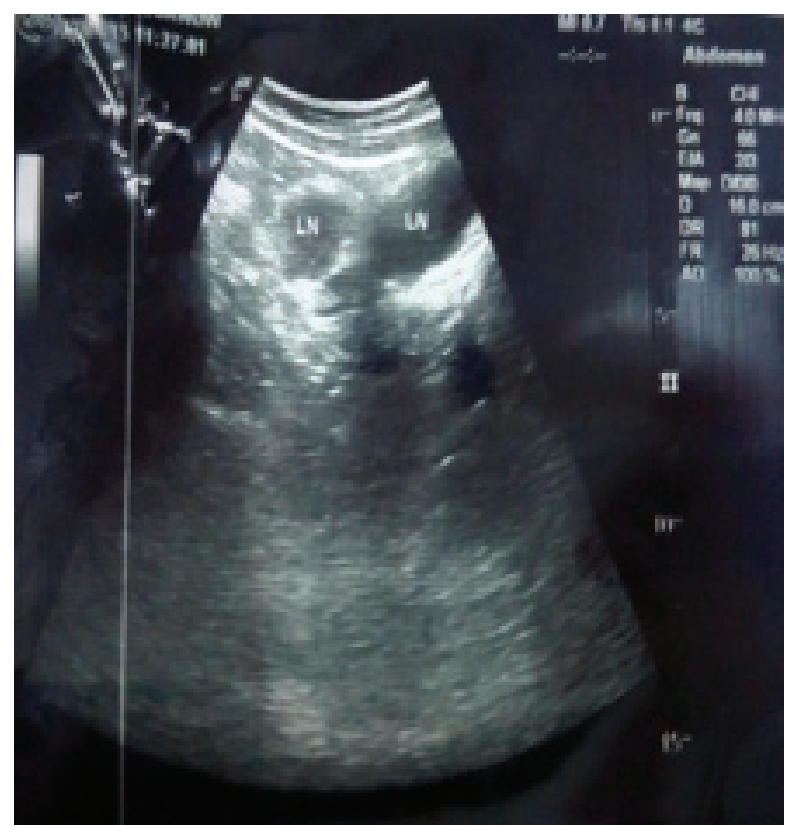

Fig 1: USG abdomen showing retro peritoneal lymphadenopathy

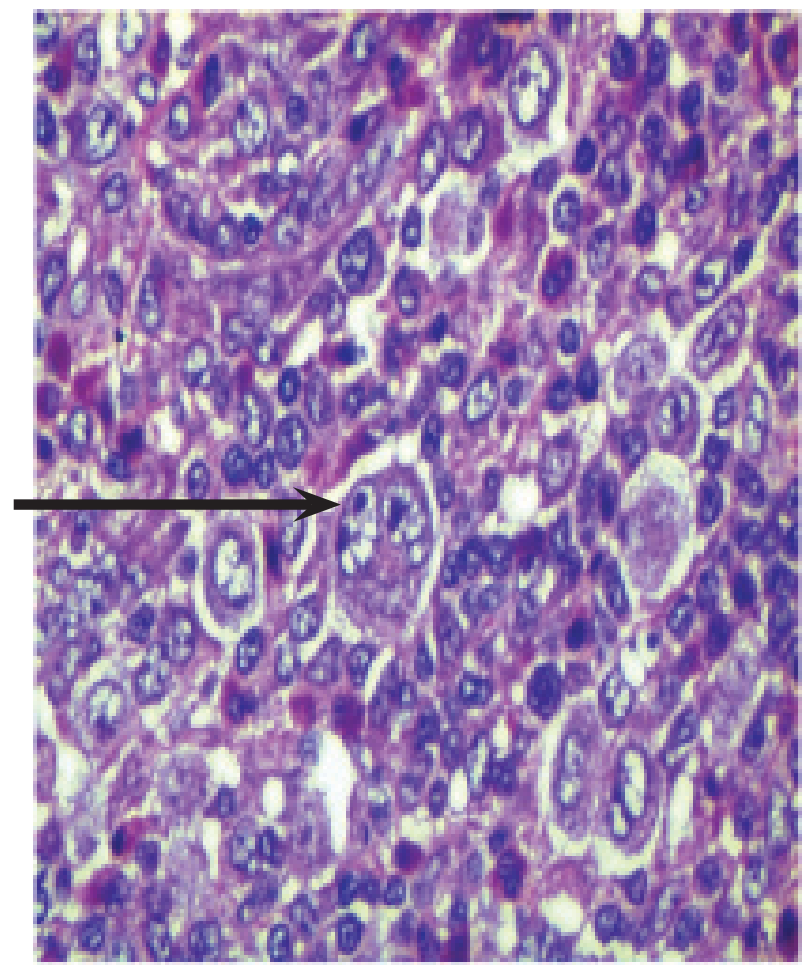

Fig 3: Histopathology of abdominal lymph node biopsy showing showing Reed Sternberg Cell

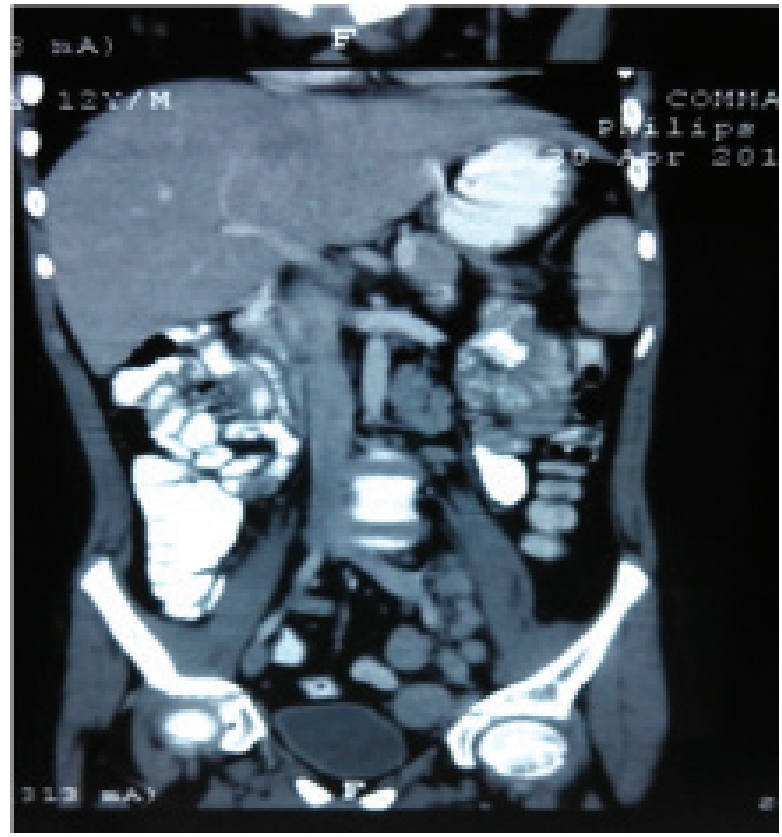

Fig 2: CECT abdomen showing para aortic \& iliac lymphadenopathy

\section{Discussion}

NS is a rare complication of Hodgkin's disease. Minimal change is most common NS seen with Hodgkin's disease. In $90 \%$ cases, NS is idiopathic. Approximately $10 \%$ cases of idiopathic NS are associated with different neoplastic disorders including solid tumours, carcinomas, lymphoma. Amongst lymphoma, nephrotic syndrome is ten times more common in patients with Hodgkin's disease.

The kidney can be involved in neoplastic diseases in many ways: direct infiltration, renal vein thrombosis, renal artery or ureter compression, biochemical abnormalities (hypercalcemia, hyperuricemia), amyloidosis and paraneoplastic disease. NS is well known as a paraneoplastic manifestation of HD and there are several cases in which the recurrence of lymphoma is reported in conjunction with a recurrent episode of $\mathrm{NS}^{8}$. The association of NS and HD having an incidence of $0.4 \%$ has been published in a large study on more than 1700 cases of $\mathrm{HD}$ and a similar percentage $(0.6 \%)$, without sex predominance, has been reported in a more recent paper on 661 children affected by $\mathrm{HD}^{9,10}$. It shows that the most common morphological subtype of $\mathrm{HD}(71.4 \%)$ is nodular sclerosis ${ }^{11}$ and MCNS is a predominant kidney disease with some rare cases of HD associated to Focal Segmental Glomerulosclerosis (FSGS), IgA nephropathy, membranous glomerulopathy (which is a type of NS predominating in solid tumours) or membranoproliferative glomerulonephritis ${ }^{10,11,12,13}$. Until now a clear pathophysiologic link between malignancy 
and renal disease has not been established, even though it is postulated that the cause of MCNS could be T cell dysfunction with abnormal secretion of cytokines, altering the permeability of the glomerular basement membrane, whereas, in case of other kidney diseases, such as membranous glomerulopathy, the pathogenesis could be mediated by immunocomplexes ${ }^{12}$. In the majority of HD cases associated with NS, selective serious albuminuria with normal renal function is the typical manifestation, with nodular sclerosis being predominant histological variety and almost ever, reversal of the renal disease is reported when the treatment against HD (chemotherapy and/or radiotherapy) results in complete remission. On the contrary, steroids, especially in NS predating

\section{References}

1. Wagrowska-Danilewicz M, Danilewicz M. Nephrotic syndrome and neoplasia: our experience and review of the literature. Pol J Pathol 2011;62:12-18.

2. Peces R, Sánchez L, Gorostidi M, Alvarez J. Minimal change nephrotic syndrome associated with Hodgkin's lymphoma. Nephrol Dial Transplant 1991;6:155-158.

3. Eagan JW. Glomerulopathies of neoplasia. Kidney Int 1977;11:297-303.

4. Alpers CE, Cotran RS. Neoplasia and glomerular injury. Kidney Int 1986;30:465-473.

5. Plager J, Stutzman L. Acute nephrotic syndrome as a manifestation of active Hodgkin's Disease. Report of four cases and review of the literature. $A m \mathrm{~J}$ Med 1971;50:56-66.

6. Stéphan JL, Deschênes G, Pérel Y, Bader-Meunier $B$, Brunat-Mentigny $M$, Lejars $O$, et al. Nephrotic syndrome and Hodgkin disease in children: a report of five cases. Eur J Pediatr 1997;156:239-242.

7. Walker F, O'Neil M, Carmody M, O'Dwyer WF. Nephrotic syndrome in Hodgkins disease. Int $\mathrm{J}$ Pediatr Nephrol 1983;4:39-41. lymphoma, are often, more or less ineffective ${ }^{11}$. However our patient responded well to prednisolone. Finally, it is our opinion that in the case of nephritic syndrome that does not respond or responds very poorly to steroid therapy or has atypical features, nephrologists should suspect an occult lymphoma.

\section{Conclusion}

Nephrotic syndrome is a common renal disease seen by paediatricians. Most of the cases are because of Minimal change disease and are managed empirically with prednisolone. However as shown in our case, the adolescents presenting with nephritic syndrome should be investigated for secondary aetiology.

8. Mori T, Yabuhara A, Nakayama J, et al. Frequently relapsing minimal change Nephrotic syndrome with natural killer cell deficiency prior to the overt relapse of Hodgkin's disease. Pediatr Nephrol 1995;9(5):619-20.

9. Alpers CE, Cotran RS. Neoplasia and glomerular injury. Kidney Int 1986;30:465-73.

10. Büyükpamukçu $M$, Hazar V, Tinaztepe $K$, Bakkaloğlu A, Akyüz C, Kutluk T. Hodgkin's disease and renal paraneoplastic syndromes in childhood. Turk J Pediatr 2000;42(2):109-14.

11. Audard V, Larousserie F, Grimbert $P$, et al. Minimal change nephrotic syndrome and classical Hodgkin's lymphoma: report of 21 cases and review of the literature. Kidney Int 2006;69(12):2251-60.

12. Gagliano RG, Costanzi JJ, Beathard GA, Sarles HE, Bell JD. The nephrotic syndrome associated with neoplasia: an unusual para neoplastic syndrome. Report of a case and review of the literature. Am J Med 1976;60(7):1026-31.

13. Mallouk A, Pham PT, Pham PC. Concurrent FSGS and Hodgkin's lymphoma: case report and literature review on the link between Nephrotic glomerulopathies and hematological malignancies. Clin Exp Nephrol 2006;10(4):284-89. 